Article

\title{
Privatization of a Tourism Event: Do Attendees Perceive it as a Risky Cultural Lottery?
}

\author{
Giuseppe Attanasi ${ }^{1}\left(\mathbb{0}\right.$, Francesco Passarelli $^{2}$, Giulia Urso ${ }^{3, *}\left(\mathbb{D}\right.$ and Hana Cosic ${ }^{4,5}$ \\ 1 GREDEG, CNRS, Université Côte d'Azur, 06560 Nice, France; giuseppe.attanasi@unice.fr \\ 2 ESOMAS, University of Turin, Baffi Centre, Bocconi University, CESIfo, 20120 Turin, Italy; \\ francesco.passarelli@unito.it \\ 3 Social Sciences, Gran Sasso Science Institute, 67100 L'Aquila, Italy \\ 4 Institute of Economics, Sant'Anna School of Advanced Studies, 56100 Pisa, Italy; hana.cosic@gmail.com \\ 5 Bureau d'Économie Théorique et Appliquée (BETA), University of Strasbourg, 67085 Strasbourg, France \\ * Correspondence: giulia.urso@gssi.it
}

Received: 2 April 2019; Accepted: 29 April 2019; Published: 2 May 2019

check for updates

\begin{abstract}
Individuals might have different views about the benefits and the costs of privatizing a cultural event. On the one hand, privatization may increase the quality of the event due to expanding investments. On the other hand, it may lead to the dissipation of important cultural and traditional connotations. Since benefits and costs are uncertain, we frame an individual's choice regarding privatization as a lottery choice, where risk aversion and other individual traits play a role. We empirically investigate attendees' preferences for privatizing a mass gathering festival in Italy. The festival is attended by almost 100,000 tourists each year. Over a three-year period, we collected a large dataset of survey questions. We find that willingness to accept privatization is decreasing in tourists' risk aversion, while it is increasing in their sensitivity to the festival's quality. Cultural tourists perceive a higher risk of commodification in the case of privatization. Authenticity-seeking tourists act as gatekeepers of the genuine roots of local traditions. They demand original values, ultimately contributing to the festival's cultural sustainability. The purpose of attracting visitors is in fact commonly assumed to alter local culture, resulting in a staged authenticity; and privatization of cultural goods is often associated with commodification.
\end{abstract}

Keywords: festival ownership; cultural tourism; sustainable tourism; authenticity; risk aversion; willingness to pay

\section{Introduction}

During the past two decades, public spending in culture has come under sharper scrutiny almost everywhere in the world due to increased budgetary constraints [1]. As a result, the supply of cultural events increasingly relies on private financial resources. In addition, economic sustainability of these events requires the implementation of new management strategies, which may also involve public-private partnerships in event ownership. The right balance between public and private ownership of a cultural event is at the heart of cultural policy, and it represents a lively debated issue. The choice of whether to privatize a cultural event or not implies a tradeoff between authenticity and financial sustainability [2]. A frequent argument against private provision of arts and culture is that it results in "commodification", i.e., turning an intrinsically social and cultural good into a mere product for sale (e.g., [3]). A counterargument is that the private management is often better at meeting consumers' needs by delivering high-quality products, which consumers are willing to pay for [4]. Since these pros and cons are both uncertain outcomes, we frame the event privatization as a lottery, toward which the event attendee forms preferences. He/she compares the expected value 
of the "risky" privatization lottery to the "sure" value of the event without privatization (the status quo). The former is a cultural lottery since both its gains-higher quality of the cultural good—and its losses-lower authenticity and cultural identity-relate to the attendee's cultural perception of the event. Relying on this model, we formulate some research hypotheses about the factors that influence an attendee's willingness to accept the privatization lottery (e.g., his/her degree of risk aversion and other psychological and idiosyncratic traits). Among all event attendees, we pay special attention to cultural tourists. In fact, "a conscious-even self-conscious-management process tries to determine cultural evolution and conservation goals" [5] (p. 557), and tourism provides vital financial resources to achieve such goals. The management of tourist flows can insure the financial sustainability of a cultural event. In turn, a tourism event's life cycle affects its management structure [6], with different public-private partnerships needed for different event editions.

To test our hypotheses, we use a large database of interviews conducted during one of the most important European festivals of traditional music ("La Notte della Taranta" in Salento, a Southern Italian region), in a period when the privatization of the event was an issue at stake. As suggested by our stylized model, we find that an attendee's monetary risk aversion is positively correlated to his/her approval of private partnership in the festival ownership. Consistent with the experimental literature on risk aversion, we also find that the willingness to accept privatization is higher amongst male and more highly educated respondents (see, e.g., [7] for gender, and [8] for education). The fact that both gender and education play a role in the predicted direction supports our idea that attendees perceive privatization as a risky choice with uncertain benefits and costs. Our findings shed light on how cultural features affect attendees' preferences for privatization. First, tourists that are "greatly (or in part) motivated" by the cultural significance of the festival per se are less willing to accept privatization. They travel to the region only for taking part in the festival and they perceive, on average, a higher risk of commodification. Furthermore, willingness to accept privatization is positively correlated to demand for quality. The more attendees are willing to pay for a quality improvement, the more they are willing to accept privatization. This result is consistent with the literature on cultural events and tourism, suggesting that privatization is likely to lead to better quality [4]. Finally, the willingness to accept privatization decreases when attendees already perceive some elements of commodification (e.g., private sponsors, advertisement, etc.). Attendees' sensitivity to authenticity and cultural aspects of the event is negatively correlated with their willingness to accept privatization only if the event is already partially commodified. This is consistent with the idea that people focus more on the negative aspects of privatization when such aspects are "visible".

The involvement of private institutions in event ownership and management is being widely debated, especially in countries where, due to the financial crisis, public funding for culture has been drastically reduced. However, to the best of our knowledge, no previous study has attempted to pin down the determinants of people's preferences regarding private vs. public ownership and management of cultural events.

The paper is structured as follows. Section 1.1 frames our research within the tourism sustainability debate. Section 1.2 presents our model and research hypotheses. Section 2.1 outlines the specific features of the event under scrutiny. Section 2.2 presents the methodological approach of the field study, mainly focusing on data collection and on the questionnaire items used to measure the variables underlying our research hypotheses. Section 3.1 provides the data analysis. A discussion of results is in Section 3.2. Section 4 concludes.

\subsection{Cultural and Economic Sustainability of Events}

Since the 1970s, there has been considerable research in the field of cultural events (for a survey, see [9]). However, studies on festival management are much more recent (e.g., [10]). Impact evaluation is the dominant topic, while event operations and management are usually analyzed through generic management concepts and methods, with the marketing perspective being at the forefront ([11-13]). The value of festivals to many places is undeniable, yet few studies have examined the challenges to 
their sustainability [6]. There has been a paucity of research to date on the governance and long-term sustainability of some kind of festivals, like rural ones, which often cope with limited resources. In this scenario, the type of ownership (i.e., private vs. public or intermediate forms of partnership) may substantially shape the attendees' experience [9], and consequently impact on festivals' tourist attractiveness [14-16]. Our study contributes to this debate. It starts from the underlying idea that authenticity and the forces of commodification necessarily operate within this conflictive arena [5]. As stressed by Cohen [2], two highly prominent discourses in the social sciences of tourism, the one relating to tourists' quest for authenticity, the other to the sustainability of tourist resources, have run in parallel throughout this literature, without engaging each other. A basic problem remains as still unexamined in author's opinion: "Does the quest for authenticity, insofar as it is a significant motive in contemporary tourism, contribute to or detract from the sustainability of tourist sites, amenities, and attractions?" ([2], p. 269). Xie and Lane [5] claim that the search for authenticity can characterize valuable niche markets (e.g., festivals), and ultimately the establishment of a carefully planned cultural heritage. According to them, "this could be the dream scenario of sustainable tourism; visitation conserves and deepens a cultural resource, acting as a tool for valorising conservation" ([5], p. 556). Examining an opera festival, Quinn [17] found that tourist audiences may prevent a festival from losing its specialist repertoire, ending up in capturing the attention of a larger public. Tourism can be crucial to ensuring financial sustainability and ultimately preserve cultural traits.

The same mechanism triggered by cultural tourists attending "La Notte della Taranta" Festival seems to be at stake, with outsiders contributing to preserve the original values of the event. Tourism may provide the impetus for communities to conserve or resurrect cultural traditions [18]. As stated also by Sims [19] (p. 322), "it is possible to use the tourist's desire for authenticity to encourage the development of products and services that will boost sustainability". Festivals are thought to provide a unique opportunity for tourists to experience authentic cultural ambience, meet local residents, and partake in something authentically indigenous $[17,18,20]$. Community festivals especially-or more generally events related to local culture with celebratory themes-are believed to be excellent examples of sustainable tourism practice. By their nature they are inclusive, inviting the general public to participate in shared cultural rituals. They provide opportunities to learn about other cultures, customs, and ways of life, which in turn encourage greater understanding and tolerance for cultural diversity [18]. A key element in tourist attractiveness is distinctiveness. Commodification erodes the more peculiar traits of a cultural good, obfuscating its distinctive features and reducing its appeal. Tourists often represent in this sense an opportunistic, incremental user group, which can bring substantial economic contribution to the event at minimal cost [18]. Theoretically, a circular mechanism can be identified: Authenticity is the source of tourist attractiveness, and tourism-especially cultural tourism-in turn helps to preserve authenticity.

While much has been written about community attitudes to tourism in general, little has been said about participants' attitude towards privatization of cultural goods. This paper addresses a relatively understudied issue: Festival attendees' opinion on alternative management formulas. Consultation is one of the tenets of sustainable tourism [21]. In this spirit, our findings may help inform tourism policy and management.

\subsection{A Simple Model of Privatization Choice}

Let $W T A_{P O}$ be an attendee's willingness to accept private ownership of a publicly owned cultural event, i.e., the cultural lottery. It may lead to higher quality due to a larger amount of financial resources (a gain) and to lower authenticity and cultural identity (a loss). Both outcomes are uncertain at the moment when attendees are interviewed. Therefore, we interpret $W T A_{P O}$ as the attendee's willingness to accept the risky "privatization lottery" against the safe status quo.

The status quo is public ownership of the event. Let $x^{S Q}$ be the cultural value of the status quo event. In order to capture the basic tradeoff of privatization, we assume that the cultural value of the event is increasing in the level of quality, $q>0$, and it is decreasing in the level of 
commodification, $c>0$. Let the cultural value of the status quo be $x^{S Q}=q^{S Q}-c^{S Q}>0$. It is greater than zero because the interviewed attendee chose to participate. Let $\ell$ be the privatization lottery. It implies a trade-off between gains from higher quality $\left(\bar{q}>q^{S Q}\right)$ and losses from commodification $\left(\bar{c}>c^{S Q}\right)$. Gains and losses of privatization are uncertain. Let $p$ be the probability that privatization yields a high value, $x^{\text {high }}=(\bar{q}-\bar{c})^{\text {high }}$. In this case, privatization is better than the status quo: $x^{\text {high }}>x^{S Q}$. Let $(1-p)$ be the probability that privatization yields a low value, which is worse than the status quo: $x^{\text {low }}=(\bar{q}-\bar{c})^{\text {low }}<x^{S Q}$. Let $u(x)$ be the attendee's utility function over the outcomes, $x \in\left\{x^{S Q}, x^{l o w}, x^{h i g h}\right\}$, with $u\left(x^{\text {low }}\right)<u\left(x^{S Q}\right)<u\left(x^{h i g h}\right)$. Therefore, the attendee's expected utility of the privatization lottery, $\ell$, is $E U(\ell)=p \cdot u\left(x^{\text {high }}\right)+(1-p) \cdot u\left(x^{\text {low }}\right)$. An attendee's willingness to accept private ownership is positive $\left(W T A_{P O}>0\right)$ if and only if $E U(\ell)>x^{S Q}$, i.e., the expected value of the privatization lottery is greater than the (sure) status quo value. Many idiosyncratic and behavioral features may affect the attendee's risky decision to take the privatization lottery. Some of our survey questions are crafted to elicit individual attitudes towards this risky choice.

The first attitude we consider is monetary risk aversion, which is related to the concavity of the utility function, $u(x)$. It is easy to see that higher risk aversion leads to lower $E U(\ell)$. A more risk-averse individual is less likely to have a positive $W T A_{P O}$. Thus he/she is less likely to accept privatization. In our questionnaire, monetary risk aversion is measured through an adaptation to a festival environment of a widely used tool in economic survey research (see [22]). Festival attendees are asked whether they would buy a lottery ticket under different pricing settings (hypothetical question). The greater their willingness to buy, the lower their degree of risk aversion. Our first research hypothesis is:

Hypothesis 1 (H1). The greater a festival attendee's willingness to buy a lottery ticket during the cultural event, the higher his/her willingness to accept private ownership of this event.

The second individual trait that we examine is attendees' willingness to pay for a quality increase in the cultural good (see [23,24]). We elicit it through a hypothetical question commonly asked in the contingent valuation literature to assess the value of a non-market good (see [25-27]). Here, we are not interested in assessing the economic value attached to the festival by participants. In line with the literature on cultural events and tourism (e.g., [4]), our aim is understanding whether attendees are willing to pay a small amount of money in order to finance a costly increase in quality. We interpret a positive answer as a statement of the value an attendee assigns to the event and to its quality. In our framework, this leads to an increase in $\bar{q}$, which in turn increases both $x^{\text {high }}$ and $x^{\text {low }}$. Ceteris paribus, this increases the expected utility of the privatization lottery, EU( $\ell)$, and ultimately $W T A_{P O}$. Thus, our second research hypothesis is the following:

Hypothesis 2 (H2). The greater an attendee's willingness to pay for a quality increase in the cultural event, the higher his/her willingness to accept private ownership of this event.

Third, we examine attendees' perception of the cultural valence of the event: Its authenticity. According to Richards [28], it should positively depend on the perception of the consistency of the event with local traditions. Therefore, participants who are more sensitive to the event's traditional features should deem commodification as highly costly. In our framework, this leads to an increase in $\bar{c}$, which in turn decreases both $x^{\text {high }}$ and $x^{\text {low }}$. Ceteris paribus, commodification decreases the expected utility of the privatization lottery, $E U(\ell)$, and ultimately $W T A_{P O}$. Thus, the third research hypothesis is:

Hypothesis 3 (H3). The greater an attendee's perception of the cultural valence of the event, the lower his/her willingness to accept private ownership of this event.

We also take a geographical perspective and examine the status of the tourist (i.e., visitors in the area of the festival), also identifying cultural tourists amongst festival participants [23,29]. A "cultural" tourist is a person who is on vacation in the area of the event also or just for it: His/her travel purpose 
is partially or fully given by the cultural event. Realistically, we assume that cultural tourists deem the commodification quite costly $[30,31]$. Their cost of commodification, $\bar{c}$, is larger than it is for the other attendees. In turn their $x^{\text {high }}$ and $x^{\text {low }}$ are lower. Ceteris paribus, their expected utility of the privatization lottery, $E U(\ell)$, and ultimately $W T A_{P O}$, are lower, compared to the rest of the sample. Therefore, our fourth research hypothesis is:

Hypothesis 4 (H4). Cultural tourists display a lower willingness to accept private ownership of a cultural event.

Finally, the cultural event we analyze is made up of two sub-events-minor concerts and the final concert-with the former being more frequently associated to local traditions (see [32]). We expect individuals to perceive a higher risk of commodification and tradition dissipation in small concerts than in the final mass gathering where commodification has, at least partially, occurred already. The fact of directly perceiving commodification while attending the event makes people consider more the negative effect of a risky privatization lottery. In other words, in the sub-sample of participants in the final concert, we expect a higher $\bar{c}$ and/or a lower perception of $p$, the latter being the probability that the privatization will bring an increase in quality greater than the increase in commodification of the cultural event. Both effects decrease the expected utility of the privatization lottery, $E U(\ell)$, and ultimately of $W T A_{P O}$. Therefore, our fifth research hypothesis is:

Hypothesis 5 (H5). The willingness to accept private ownership of a cultural event is lower if the traditional connotation of the event has already been partially lost.

\section{Data and Methods}

\section{1. "La Notte della Taranta" Festival: Objective, Structure, and Ownership}

"La Notte della Taranta" Festival (henceforth, Festival) is a folk music event first held in 1998 on the initiative of the municipalities of Grecia Salentina, a linguistic and cultural sub-area within the peninsula of Salento, in Southern Italy. The main objective of the Festival is to preserve and promote local cultural heritage, with a particular focus on the traditional musical repertoire called "pizzica salentina". Since 2005, the Festival has gained in popularity, with its audience reaching more than 100,000 participants per year (around 400,000 in 2018). The Festival takes place in mid-August and is made up of two sub-events closely connected to one another. The first sub-event consists of a series of 13 to 15 itinerant concerts (henceforth, minor concerts), with the number of attendees per concert ranging between 2000 and 10,000 in the editions of 2007 to 2009. Minor concerts take place once per day over a time span of about two weeks in a different village of Grecia Salentina. The second sub-event is a mass gathering held every year at the end of the series of minor concerts (henceforth, final concert), with the number of attendees ranging between 100,000 and 150,000 in the editions of 2007 to 2009. While minor concerts better preserve the aspects of tradition and familiarity typical of "village feasts", this traditional connotation is weaker in the final concert, due to both music contamination and the more heterogeneous attendees' geographic origins: One of the villages of the area is transformed into a one-night, huge dance floor with a prevalence of non-local participants. The attendance to all Festival concerts is free.

As regards Festival management, at the time of our survey it was entirely run by local public institutions. According to an agreement signed in 2005, the Festival organizers were: Apulia Region, Province of Lecce, Union of Municipalities of Grecia Salentina, and Carpitella Institute (publicly financed anthropologic research center). As regards the Festival ownership structure, when we started our survey in 2007, the above-mentioned local public institutions mutually held the Festival property rights. In that specific moment, "La Notte della Taranta" Festival was not only the subject of an animated discussion on the privatization of cultural heritage, but it was also the object of a heated local and regional public debate concerning the choices that organizers had to make between going for private ownership or establishing a public foundation. Therefore, our field study of the attendees' 
willingness to accept private ownership was highly relevant for informing the Festival decision makers about pros and cons of this choice, and it actually turned out to be the creation of a foundation to manage the event. This occurred in 2010, i.e., after the last surveyed year of our field research.

Given the aim of this paper, the establishment of an ad hoc foundation in 2010 accountable for the Festival management is a relevant event. Its founding members (still in place today) are the same above-mentioned local public institutions that started the project of the Festival. It is a participatory foundation: The statute foresees the potential involvement and participation, though for an overall share not exceeding $20 \%$ of the shared capital, of other public or private institutions, entities, or enterprises as well as natural persons who meet the requirements needed to join the Foundation and support its work (See www.lanottedellataranta.it/en/the-foundation/foundation). With regard to Festival financing, our 2007 to 2009 field study was relevant because of the contingency of a general climate of instability due to the great recession and a decrease of public financing for culture. Table 1 shows that the costs for the event were progressively reduced from 2007 to 2009.

Table 1. Costs of the Festival (in $€$ ) from 2007 to 2009, classified according to the nature and sub-events.

\begin{tabular}{cccccc}
\hline \multicolumn{4}{c}{ Nature (N) } & \multicolumn{2}{c}{ Sub-event (S) } \\
\hline $\begin{array}{c}\text { Festival } \\
\text { Editions }\end{array}$ & $\begin{array}{c}\text { Music } \\
\text { Performers }\left(\mathbf{N}_{\mathbf{1}}\right)\end{array}$ & $\begin{array}{c}\text { Other } \\
\left.\text { Expenses } \mathbf{( N}_{\mathbf{2}}\right)\end{array}$ & $\begin{array}{c}\text { Minor } \\
\text { Concerts }\left(\mathbf{S}_{\mathbf{1}}\right)\end{array}$ & $\begin{array}{c}\text { Final } \\
\text { Concert }\left(\mathbf{S}_{\mathbf{2}}\right)\end{array}$ & $\left.\mathbf{( N}_{\mathbf{1}}+\mathbf{N}_{\mathbf{2}} \mathbf{)}=\mathbf{( S}_{\mathbf{1}}+\mathbf{S}_{\mathbf{2}}\right)$ \\
\hline 2007 & 401,015 & 783,540 & 355,366 & 829,189 & $1,184,555$ \\
2008 & 260,440 & 661,128 & 276,470 & 645,098 & 921,568 \\
2009 & 228,710 & 578,149 & 242,058 & 564,801 & 806,859 \\
\hline
\end{tabular}

Costs are classified according to their nature-expenses for music performers and "other expenses"—and the specific sub-event they refer to-expenses for minor concerts and expenses for the final concert.

Table 2-summarizing Festival financing for the three editions of 2007 to 2009 (data obtained from, and certified by, festival organizers) - shows that although the majority of funds are provided by different public bodies, they were, overall, contributing less and less in the same period. In 2009, the situation was worsened by the ending of the EU funding. Municipalities gathered under the "Union of Municipalities of Grecia Salentina" had to compensate for these losses while the share of private financing $(25 \%)$ was the only one to be stable over time. Private financing has never overcome $25 \%$ in all editions of the Festival up to 2018, being maximum in the three editions analyzed in this paper.

Table 2. Funding sources of "La Notte della Taranta" Festival.

\begin{tabular}{|c|c|c|c|}
\hline Financing Partners & $\begin{array}{c}\text { Expenses for } 2007(€): \\
1,184,555\end{array}$ & $\begin{array}{c}\text { Expenses for } 2008(€): \\
921,568\end{array}$ & $\begin{array}{c}\text { Expenses for } 2009(€) \text { : } \\
806,859\end{array}$ \\
\hline European Union & $17 \%$ & $12 \%$ & $0 \%$ \\
\hline Apulia Region & $35 \%$ & $20 \%$ & $22 \%$ \\
\hline Province of Lecce & $10 \%$ & $20 \%$ & $9 \%$ \\
\hline $\begin{array}{c}\text { Union of Grecìa } \\
\text { Salentina }\end{array}$ & $10 \%$ & $20 \%$ & $40 \%$ \\
\hline Chamber of Commerce & $3 \%$ & $3 \%$ & $4 \%$ \\
\hline Private firms & $25 \%$ & $25 \%$ & $25 \%$ \\
\hline
\end{tabular}

The promiscuity and variability of the financing sources in Table 2 show that the realization of the Festival from 2007 to 2009 relied on an unstable fundraising mechanism, which justified the relevance of the issue of the privatization of Festival ownership. Our study tackled this matter from the perspective of Festival attendees.

\subsection{Methodology}

From a methodological point of view, while many previous studies have approached cultural goods using non-market valuation techniques, such as contingent valuation, our study goes beyond the 
mere estimate of the event's economic value. It combines experimental economic tools on risk aversion elicitation (see [33]) with insights from the geographical perspective on social effects of events (see [34]) framed within the sustainability discourse. More precisely, we conducted a three-year field study (2007-2009) during the most important publicly financed folk festival dedicated to traditional music in Italy and Europe: "La Notte della Taranta" Festival, which we thoroughly described in Section 2.1. Table 3 shows the number of interviews during each of the editions of 2007 to 2009 and the estimated number of participants in each of them. Sample representativeness was controlled through a Marbach test ([35]) (The Marbach test associates the pair of variables, $N$ (size of the target population) and $n$ (sample size), with a parameter, $x$, that specifies the tolerated margin of error occurring when the sample of a size, $n$, is taken as being representative of the whole population. In the literature, values of $x$ lower than 0.05 are considered as acceptable). Our sample proved to be representative of the target population with the sample probability oscillating between $95 \%$ and $98 \%$ (margin of error between $2 \%$ and 5\%). A sample of 7371 attendees of the Festival out of a total of around 554,500 (with more than half being tourists) were interviewed over the three editions of 2007 to 2009. In each edition, the survey period covered the whole duration of the Festival, usually ranging from the second till the last week of August.

Table 3. Population, sample, and its representativeness.

\begin{tabular}{cccccc}
\hline \multirow{2}{*}{ Edition } & Sub-event & $\begin{array}{c}\text { Estimated } \\
\text { Population }\end{array}$ & $\begin{array}{c}\text { Estimated } \\
\text { Tourists }\end{array}$ & Sample Size & $\begin{array}{c}\text { Margin of Error } \\
x=\sqrt{\frac{N}{(N-1) n}-\frac{1}{N-1}}\end{array}$ \\
\hline \multirow{2}{*}{2007} & Minor Concerts & 68,000 & 40,000 & 2172 & 0.02 \\
& Final Concert & 100,000 & 67,500 & 704 & 0.04 \\
\multirow{2}{*}{2008} & Minor Concerts & 71,500 & 43,500 & 483 & 0.04 \\
& Final Concert & 150,000 & 102,000 & 416 & 0.05 \\
& Minor Concerts & 65,000 & 28,000 & 2596 & 0.02 \\
& Final Concert & 100,000 & 67,800 & 1000 & 0.03 \\
\hline
\end{tabular}

Our combination of experimental tools with methods specific to cultural economics and tourism/event studies provides two related methodological contributions to the investigation of consumers' stated preferences on tourism management issues. First, attendees' willingness to accept private partnership in a festival ownership was elicited during the consumption of the cultural good. In terms of our model in Section 1.2, this is essential to operationalize the assumption that an interviewee considers the status quo value of the cultural good as an alternative option to the privatization lottery. We assume the latter to be positive since the interviewee has chosen to consume that good (by attending the Festival). Interviews were conducted by graduate students previously trained by two of the authors of this paper. Each interviewee was randomly and independently selected among concert attendees, and people from the same group or who had already been interviewed during previous concerts or editions were not included. The sequence of questions as well as the list of possible answers to each question were presented in opposite order to half of the sample, so as to check for order effects in interviewees' answers. Moreover, a series of control questions was introduced in order to assess respondents' level of attention during the interview and the reliability of their answers. Each interview took from 7 to $10 \mathrm{~min}$ to be completed, depending on whether interviewees were residents or tourists (for the latter, some additional questions were included). Second, we implemented a between-subject design to interview customers consuming a good that might be differently perceived in its cultural dimension. Indeed, as already explained in Section 2.1, "La Notte della Taranta" Festival consists of two closely related sub-events (a series of "small" itinerant concerts—minor concerts—and a final mass gathering-final concert). As mentioned earlier in Section 1.2, minor concerts are more likely to be interpreted as genuine and close to local culture compared to the final concert. Such a different perception is probably due to a process of commodification, which already affected the final concert and which started earlier. Ever since the first edition 10 years earlier, the final concert has 
been characterized by music and style contamination (rock, jazz, pop, etc.), less use of traditional musical instruments, a highly technological stage and sound diffusion, huge media coverage, and the advertisement of non-local products and firms eventually financing the event.

Table 4 shows that the number of interviews that we conducted during minor concerts and the final concert are comparable numbers: Both samples are highly representative for each year we considered. This between-subject design allowed us to test hypothesis H5. (see Section 1.2); i.e., attendees are more prone to accept privatization when cultural connotation has already been partially dissipated (as in the final concert). Table 4 also shows that the estimated percentage of tourists in 2007 to 2009 ranges from $43 \%$ to $61 \%$ in minor concerts and is constant at $68 \%$ in the final concert. The fact that both the absolute and the relative number of tourists at the Festival were significantly higher during the final concert allowed us to test whether (lower) cultural connotation and (higher) tourist attractiveness interplay in shaping attendees' preferences for private ownership of the event.

Table 4. Variables, questionnaire items, and literature references.

\begin{tabular}{|c|c|c|}
\hline Variable & Item & Literature \\
\hline (H1) Monetary risk aversion & $\begin{array}{l}\text { [Low lottery] Would you agree to } \\
\text { pay a ticket of } 0.5 / 2.0 \text { euros to create } \\
\text { a fund that, at the end of the evening, } \\
\text { is assigned to a person drawn at } \\
\text { random among } 100 \text { participants? } \\
\text { Yes/No/I don't know } \\
\text { [High lottery] Would you agree to } \\
\text { pay a ticket of } 5.0 / 7.0 \text { euros to create } \\
\text { a fund that, at the end of the evening, } \\
\text { is assigned to a person drawn at } \\
\text { random among } 100 \text { participants? } \\
\text { Yes/No/I don't know }\end{array}$ & $\begin{array}{l}\text { Adaptation to a festival environment of a } \\
\text { widely-used tool in economic survey } \\
\text { research (see [22]). }\end{array}$ \\
\hline $\begin{array}{l}\text { (H2) Willingness to pay for a quality } \\
\text { increase in the cultural good }\end{array}$ & $\begin{array}{l}\text { Would you agree to pay a small price } \\
\text { to participate in a cultural event like } \\
\text { this one if the quality improved? }\end{array}$ & $\begin{array}{l}\text { For willingness to pay for a cultural good, } \\
\text { see [24]. For willingness to pay for quality } \\
\text { improvement in different sectors (e.g., } \\
\text { public services), see }[36,37] \text {. }\end{array}$ \\
\hline $\begin{array}{l}\text { (H3) Perception of the cultural and } \\
\text { traditional dimension of the event }\end{array}$ & $\begin{array}{l}\text { What is your opinion on "La Notte } \\
\text { della Taranta" Festival? } \\
\text { — cultural event: Yes/No } \\
\text { — folk/traditional event: Yes/No }\end{array}$ & $\begin{array}{l}\text { For the relevance of the perception with } \\
\text { regard to the level of authenticity of } \\
\text { cultural events, see [38]. }\end{array}$ \\
\hline (H4) Status of cultural tourist & $\begin{array}{l}\text { [only to tourists] } \\
\text { Why are you in Salento? } \\
\text { —On holiday: Not for the event } \\
\text { [non-cultural tourist]/also for the } \\
\text { event/just for the event [cultural } \\
\text { tourist] } \\
\text { - } \ldots \ldots \text {... }\end{array}$ & $\begin{array}{l}\text { Cultural tourism is defined as visits by } \\
\text { persons from outside the host community } \\
\text { motivated wholly, or in part, by interest in } \\
\text { the historical, artistic, scientific, or } \\
\text { lifestyle/heritage offerings of a } \\
\text { community, region, group, or institution. } \\
\text { We consider as cultural tourists those } \\
\text { tourists who are either greatly or in part } \\
\text { motivated by culture [39]. }\end{array}$ \\
\hline (H5) Sub-type of event attended & $\begin{array}{l}\text { Retrieved from the front page of the } \\
\text { questionnaire }\end{array}$ & {$[32]$.} \\
\hline
\end{tabular}

In the questionnaire, the following question asks the attendee's willingness to accept private ownership $\left(W T A_{P O}\right)$ of the Festival: "Would you agree if the private sector contributed to organize and manage a popular cultural event, making profits from it?". Table 4 indicates the questionnaire item(s) used to measure the variables on which hypotheses H1. to H5. rely. The first variable relies on the behavioral-economic literature, while the remaining four ones draw on tourism and event studies. The table also reports references to the literature supporting our empirical strategy. Below, we discuss the operationalization of each research hypothesis through the related item(s) in the questionnaire.

(H1.) Monetary risk aversion. Each interviewee was faced with a hypothetical situation where he/she was asked to choose whether or not to buy a ticket, thereby contributing to create a fund. This fund would be randomly assigned to one out of 100 subjects (including the interviewee) who were attending the concert and had bought the ticket as well (see Table 4). This hypothetical situation 
was proposed twice to each interviewee, with a low-price lottery, L, (with price $€ 0.5$ or $€ 2$ ) and with a high-price lottery, $\mathrm{H}$, (with price $€ 5$ or $€ 7$ ). The order in which the two lotteries were presented to the interviewees was inverted for half of them so as to control for order effects. From a theoretical point of view, for both lotteries, $\mathrm{L}$ and $\mathrm{H}$, a risk-neutral subject should be indifferent about buying the lottery ticket or not. A risk-averse subject should buy none of the two (both variables, lottery L and lottery $\mathrm{H}$ take a value of 0 ), with the unwillingness to buy the ticket being higher for the high-price lottery. A risk-seeking subject should buy both lottery tickets (both variables, lottery $\mathrm{L}$ and lottery $\mathrm{H}$, take a value of 1), with the willingness to buy being higher for the high-price lottery. Note that the variable, lottery $\mathrm{L}$ and lottery $\mathrm{H}$, measure the willingness to participate in a monetary lottery, which should positively correlate with $W T A_{P O}$. The latter refers to the cultural (privatization) lottery introduced at the beginning of Section 1.2.

(H2.) Willingness to pay for a quality increase in the cultural good. The related questionnaire item in Table 4 elicits whether an attendee is willing to pay a small amount of money in order to finance the cost of a quality increase. The binary variable (WTP for quality increase) assumes a value of 1 in the case of a positive answer. Although this willingness to pay is elicited through a hypothetical question, experimental tests of this specific instrument have proved its reliability. In fact, Camacho-Cuena et al. [25,26] showed that- - though potential distortions may emerge compared to a real-incentive elicitation instrument-the measurement bias at an aggregate level is not significant. An alternative method consists in asking the willingness to accept a price against quality improvement. Georgantzís and Navarro-Martínez [27] showed that the willingness-to-accept-willingness-to-pay gap depends on some responder's idiosyncratic features and on his/her familiarity with the product under scrutiny.

(H3.) Perception of the cultural and traditional dimension of the event. Traditional event and cultural event are two binary variables taking value 1 , respectively, if the attendee declares that the sub-event he/she is attending is linked to local traditions and if he/she deems it as intrinsically cultural.

(H4.) Status of cultural tourist. We identify cultural tourists by combining answers to two questionnaire items. First, we rely on the one detecting place of residence: We ask the Festival attendee where he/she usually lives during the year. If he/she usually lives in the area where the event is held (i.e., village hosting the Festival or Province of Lecce), then we classify him/her as a resident. If he/she usually lives outside this area (i.e., elsewhere in Apulia, Italy, or abroad), then we define him/her as a tourist. Then, only to this latter sub-sample, we address the question on intensity of Festival-related motivation (see Table 4). Thus, tourists are classified in three sub-groups: Participants who are on summer vacation in the area where the Festival is held for reasons that are not related to the Festival (not motivated tourists); those who are on vacation in the region also for the Festival (in part motivated tourists); and just for the Festival (greatly motivated tourists).

(H5.) Minor concerts vs. final concert. As anticipated above, our between-subject design allows us to identify the effect of a higher perception of commodification on $W T A_{P O}$ produced by the final concert, by just disentangling attendees interviewed at one of the minor concerts and those interviewed at the final concert (see Table 3).

A second set of explanatory variables includes controls for individual characteristics, i.e., participants' idiosyncratic features not related to Festival attendance: Gender, education, age, and place of residence. For gender, we recorded males vs. females. The ordinary variable of education indicates the attendee's last educational attainment: Primary school, secondary school, high school, university degree, and postgraduate degree. The ordinary variable of age classes attendees into five categories: "Under 25", "between 26 and 30", "between 31 and 40", "between 41 and 60 ", and "over 60" years old. For the ordinary variable of residence, as anticipated when describing the operationalization of H4., we distinguished five categories. The first two define residents (attendees living for most of the year in the village or in the area where the Festival takes place, i.e., Province of Lecce). The remaining three define regional, national, or foreign tourists (respectively, attendees living in Apulia - the administrative region of Southern Italy where the Festival is held-Italy, or any foreign country). 
As an additional control, in this case related to the specific context where our field study was conducted, we considered instantaneous social capital. We asked every attendee whether a person he/she does not know, for the mere fact of participating in the same concert he/she is attending at the Festival, deserves to be trusted more than another person he/she does not know and who is not attending that concert. This instantaneous social capital is a binary variable taking a value of 1 for positive answers. The reason why we included this variable is because other field studies of the same Festival proved this additional (Festival-related) trust in other attendees to correlate with attendee's alcohol consumption during the Festival ([40], in 2012-2017) and with the Festival's socio-economic impact ([32], in 2007-2011) (The dataset of this paper partially overlaps with the one used in [32]. Both datasets are based on the same questionnaire used to interview attendees to the Festival. However, Attanasi et al. [32] focused on that part of the questionnaire aimed at assessing the socio-economic impact of the Festival on the region where it is held and its sociological effects on people taking part in the concerts. Conversely, this paper analyzes questions designed to investigate participants' willingness to accept private ownership of the Festival. Indeed, the data analysis in Section 3 considers variables that are specific to this issue, which are not considered in [32].). However, according to our model in Section 1.2, an attendee's instantaneous social capital might have opposite effects on his/her $W T A_{P O}$. On the one hand, following the literature on the negative correlation between trust and risk aversion [22], a greater trust on other festival attendees-via a higher risk proneness-increases WTAPO. On the other hand, given the link between instantaneous social capital and the cultural dimension of the event found in [32] and [41] for the same event analyzed in our study, this instantaneous trust leads to an increase in the perception of commodification cost, thereby decreasing $W T A_{P O}$. This is why we only used this variable as a control.

Finally, we included two binary time variables for data collected across the survey years, 2007 and 2008, so as to determine any trend during the three-year survey (2007-2009) (The questionnaire items used in the data analysis of Section 3 have been validated, for different research questions, by Attanasi et al. [32], whose questionnaire has the same core items as ours and ranges over the time span of 2007 to 2011. As a further step, we checked our dataset for internal validity of the questionnaire items that we have used for research hypotheses H1. to H5. and for additional controls).

\section{Results}

\subsection{Data Analysis}

In accordance with the experimental economic literature, we found: A positive (Spearman's rank) correlation between low-price lottery, L, and high-price lottery, $\mathrm{H}(p$-value $<0.000)$, and between the latter and both male gender ( $p$-value $<0.05$ ) and instantaneous social capital ( $p$-value $<0.000)$; a significantly higher disclosed monetary risk aversion (Chi-Square test, $p$-value $<0.000$ ) across attendees at the final concert than at the minor concerts, according to both the low-price lottery, L, and high-price lottery, $\mathrm{H}$. In line with the cultural economic literature, we found a significantly higher perception of the cultural dimension of the event (Chi-Square test, $p$-value $<0.05$ ) across cultural (greatly or in part motivated) tourists than across non-cultural (not motivated) tourists.

Despite the public nature of the Festival (the status quo), a large share of attendees declared they would be willing to accept privatization, with a positive difference between minor concerts $(44 \%)$ and the final concert $(38 \%)$, significant at $1 \%$. Our data are consistent with H5. since they support our hypothesis that attendees perceived a difference in the nature of the two sub-events in terms of the link with local traditions, in favor of minor concerts. For instance, $35 \%$ of attendees of minor concerts vs. $33 \%$ of attendees of the final concert claimed they participated in the event because of the traditions it embodies (difference significant at 10\%). Also, final concert attendees declared they were more attracted by the opportunity to be together and be entertained with many people ( $44 \% \mathrm{vs} .31 \%$ in minor concerts, significant at $1 \%$ ). This is proof of the mass gathering dimension of the final concert, with a significantly higher fraction of tourists (68\% vs. $55 \%)$ in the audience. 
Results in Table 5 report a probit regression predicting the outcome of $W T A_{P O}$. The research hypotheses elaborated in Section 1.2 were tested on the data of our field study as described in Section 2.2. Coefficients refer to the marginal effects of the explanatory variables described at the end of Section 2.2. In aggregate regressions (i.e., on data obtained through interviews from both minor concerts and the final concert), we added a dummy taking a value 1 for attendees interviewed during the final concert. Furthermore, in order to capture specific effects due to the type of sub-event, we also ran separate regressions for minor concerts and the final concert. Concerning cultural tourists, the variable of not motivated tourists was excluded from the regression to avoid collinearity.

Table 5. Probit regression, willingness to accept private ownership (WTAPO).

\begin{tabular}{|c|c|c|c|}
\hline & \multicolumn{2}{|c|}{ Separate Regressions } & \multirow[t]{2}{*}{ Joint Regression } \\
\hline & Minor Concerts & Final Concert & \\
\hline Lottery H & 0.130 & $0.325^{* *}$ & $0.178^{* *}$ \\
\hline Lottery L & $0.180 * *$ & 0.042 & $0.138^{* *}$ \\
\hline WTP for Quality Increase & $0.293^{* * *}$ & 0.007 & $0.213^{* * *}$ \\
\hline Cultural Event & -0.167 & 0.204 & -0.022 \\
\hline Traditional Event & 0.130 & $-0.296 *$ & -0.027 \\
\hline Greatly Motivated Tourists & $-0.261^{* *}$ & 0.150 & 0.030 \\
\hline In Part Motivated Tourists & -0.074 & $-0.276^{* *}$ & $-0.144^{* *}$ \\
\hline Final Concert (dummy) & - & - & $-0.106^{*}$ \\
\hline Male & $0.216^{* * *}$ & 0.094 & $0.179^{* * *}$ \\
\hline Education & $0.140^{* * *}$ & 0.088 & $0.125^{* * *}$ \\
\hline Age & 0.007 & 0.066 & 0.023 \\
\hline Residence & 0.132 & -0.100 & 0.085 \\
\hline Instantaneous Social Capital & 0.022 & 0.025 & 0.018 \\
\hline Year 2007 & -0.078 & -0.137 & -0.093 \\
\hline Year 2008 & -0.074 & -0.229 * & -0.134 \\
\hline
\end{tabular}

***: significant at $1 \%$; **: significant at $5 \%$; : significant at $10 \%$.

\subsection{Discussion}

As for H1., by looking at the joint regression in Table 5, the coefficients for both high-price and low-price lottery-which measure attendees' risk proneness-are positive and significant (at the 5\% level), showing that more risk-taking attendees are more likely to accept Festival private ownership: A lower monetary risk aversion presumably leads to an underestimation of the commodification risk-expected costs/losses of the risky privatization lottery. Concerning H2., if an attendee is more willing to pay for a quality improvement of the cultural good-expected gains of the privatization lottery-then he/she is more willing to accept Festival private ownership. This effect (significant at 1\%) opposes a substitution effect of the kind "if I pay for a public good (e.g., a cultural event), I do not want private firms to manage and/or invest in it". We do not find strong support for H3. The variable of cultural event shows no significant effect on $W T A_{P O}$, presumably because more than $9 / 10$ attendees perceive the Festival as a cultural event, independently of whether they were interviewed during the final or the minor concerts. The variable of traditional event shows a significant negative effect on $W T A_{P O}$ only for the final concert, where perceptions of the event as being consistent with local traditions have been eroded. Privatization of the final concert is deemed riskier than for minor concerts. One possible explanation is that commodification is more likely to occur in large mass gathering events than in smaller ones. The latter are probably deemed stronger in holding their traditional traits against commodification. This side effect is not experienced by minor concert attendees.

We find evidence of the validity of H4. Table 5 reports a negative and significant coefficient (at $5 \%$ ) for in part motivated tourists. However, the status of greatly motivated tourists, whose Festival-related motivation is higher since they chose the destination just for the event, seems to make no difference at an aggregate level. The reason for this apparent inconsistency becomes clearer after observing 
separate regressions. Indeed, while in minor concerts the variable greatly motivated tourists negatively influences $W T A_{P O}$, in the final concert this occurs for in part motivated tourists (both effects are significant at $5 \%$ ). According to our model, the preference for public ownership should be stronger the higher the Festival-related motivations are, i.e., for greatly motivated tourists who were "pushed" to travel to the area by the Festival itself. They should not be disposed to run the risk of seeing their unique source of attraction as a place being pillaged of its own nature because of private ownership (and profit). Also, greatly motivated tourists "paid" more than other attendees in terms of travel and accommodation expenses in order to enjoy the Festival. This is where a sunk cost fallacy steps in: They paid these costs so as to obtain a sure payoff, the Festival as it is, and they would not accept this payoff to be decreased by private ownership. This hypothesis is supported in the case of greatly motivated tourists attending minor concerts, but it does not hold for the final concert. This could be because greatly motivated tourists attending the Final Concert cannot be considered as "pure" cultural tourists: $53 \%$ of them claim they attend the event because of its "entertainment" side and only $28 \%$ (difference significant at 1\%) for its "traditional" connotation. Their view of the Festival is less related to traditional and cultural features, and this is arguably why they do not perceive a true risk of commodification in the case of private ownership. Conversely, in part motivated tourists attending the final concert have a lower "entertainment" motivation ( $48 \%$, difference not significant) and a greater cultural motivation (38\%, difference significant at $10 \%)$ than greatly motivated tourists at the same event. Furthermore, they state they decided to visit the area where the Festival is held not only for the final concert, but also for other reasons linked to the attractions of that area. Their linkages to local culture are strong and lead them to feel more the risk of cultural depletion due to a Festival's private ownership. This is why $W T A_{P O}$ at the final concert is negatively related to the status of being an in part motivated tourist.

Finally, our findings substantiate H5.: The marginal effect on $W T A_{P O}$ of the final concert dummy is negative and significant (at 10\%), showing a smaller openness to private ownership when part of the cultural connotation has already been dissipated. This conclusion is also supported by other evidence from Table 5. In the separate regression for minor concerts only, lottery L has a significant positive effect on $W T A_{P O}$, while the effect of lottery $\mathrm{H}$ is not significant. The opposite holds in the separate regression for the final concert. Therefore, the willingness to pay a low-price lottery ticket is sufficient to significantly increase $W T A_{P O}$ in minor concerts, while willingness to pay a high-price lottery ticket-i.e., a disclosed higher degree of risk propensity-is needed to significantly increase $W T A_{P O}$ in the final concert. This provides indirect evidence that the final concert environment is perceived as "riskier" than the one characterizing minor concerts.

We conclude by examining the control variables in Table 5. Our results on the role of attendees' general idiosyncratic features on $W T A_{P O}$ are in line with the above-mentioned literature on the correlation between risk aversion and gender (see [42]) or education (see [43], for financial decisions; [44], for consumer choices). On average, the degree of risk aversion of males and highly educated people is lower. We find that both these results also apply to the "risk" of private ownership of a cultural event, with male and highly educated attendees being more open to accept this "cultural" risk (effect significant at $1 \%$ ). We find no significant effect of either age or place of residence on $W T A_{P O}$. The latter result, combined with what shown above for H4., indicates that being a tourist or a resident in the area of the Festival makes no difference for an attendee's $W T A_{P O}$, whereas his/her travel motivation does. Furthermore, as for instantaneous social capital, we find no significant impact on WTAPO in either the aggregate regression or in each of the two sub-events separately considered. This seems to validate the discussion at the end of Section 2.2 about possible contrasting effects of instantaneous social capital on $W T A_{P O}$, via a positive correlation with monetary risk aversion vs. a higher perception of commodification. Finally, a positive trend is detected in the survey year of 2009 as compared to 2007 and 2008, although it is significant (at 10\%) only for the final concert and only in 2008. 


\section{Conclusions}

The organization of a festival of traditional culture gathering a large mass of tourists usually requires huge economic investments as well as strong management skills. Most frequently, such cultural events are publicly provided. Private provision (via private ownership or sponsorship) may ensure additional financial resources. However, it may come at the cost of dissipating the main cultural and traditional traits of the event. More generally, privatization of cultural events is both an extremely important policy issue and a risky choice at the same time [45].

In this paper, we studied the demand side of that choice, with specific relation to a traditional music festival in Southern Italy: "La Notte della Taranta" Festival. Provision by private institutions may increase the availability of financial resources, especially when public funding for culture is scarce. Festival ownership could be a crucial variable for the success of the event, especially when public funding for culture reduces in times of economic crises. We studied empirically attendees' willingness to accept the privatization of the festival. This issue is at the heart of a recent debate about the extent to which private capital should be included in the ownership and management of culture and what risk this entails for the independence of culture itself. We argued that this kind of risk enters individual preferences for private ownership, as in a sort of lottery. We therefore expected that factors determining individuals' general attitude towards risk play a role in their preferences for the private ownership of cultural events, too. Our analysis empirically substantiated this hypothesis under a specific circumstance: The contraction of public spending for culture. Our paper did not aim to find some generalization on the most common people's attitude to the privatization of heritage. Rather, it investigated it under a particular state of the world: A period of economic recession and contraction of public spending, when the topic became more salient, as it was also the case for our target cultural event during our three-year survey (2007-2009) (see Section 2.1). In fact, the financial crisis which started developing in summer 2007 in the US, strongly affected the EU economy from autumn 2008, with the government deficit to GDP ratio reaching its peak level in 2009. The crisis had an impact on the real economy in the EU through connections to the financial system, wealth and confidence effects on demand, and through global trade [46]. According to the OECD [47], the recession in Italy has been longer and deeper than in most EU countries (in 2007, real GDP rose by 1.33\%; in 2008, declined by $1.07 \%$; and in 2009 , by $5.58 \%$ [48]. The unemployment rate rose from $6.07 \%$ in 2007 to $6.72 \%$ in 2008 and to $8.07 \%$ in 2009 [48]. Analysis of the government deficit to GDP ratio for the period of 2007 to 2009 showed a rising trend from $1.5 \%$ in 2007 to $2.7 \%$ in 2008 and to $5.3 \%$ in 2009 [49]). Also, the period of 2007 to 2009 was a season of political instability in Italy (in 2008, Italian Prime Minister, Romano Prodi, lost a confidence vote and Silvio Berlusconi and the Right regained power).

This might represent a possible limitation to our study. We are aware that the climate of uncertainty could alter public perception on the privatization of non-market goods, although, to the best of our knowledge, there is no evidence in the literature that people's attitudes toward privatization is a function of periods of prosperity or economic slowdown (rather, the reverse was found in Poland in 1991 to 2014 [50]). Under the above circumstances of economic downturn, our data showed that people are less prone to accept privatization if the risk of a potential loss in its more genuine cultural dimension is perceived as high. We also showed that this effect is greater if the cultural event has already lost part of its original traditional connotation, i.e., in the festival's final mass gathering, where the presence of cultural tourists is higher in both absolute and relative terms. Our data showed that individuals perceive privatization not only as an instrument to increase quality, but also as a risk of commodification, a loss of authenticity, and cultural valence. This in turn may significantly lower the festival 's attractiveness to tourists. However, it is worth underlying that this issue could be a priori more relevant for residents than for tourists, who are eventually not aware of the financing formula of the event they are participating in or, if they are, could not be necessarily concerned about it. This is another possible limitation of our study.

People's attitude towards privatization of local cultural events has been largely overlooked by existing theoretical and empirical research in tourism and event management. This is surprising 
since it is a crucial issue for any country willing to ensure long term sustainability of its cultural heritage. Tourism is an important source of financial resources. However, engagement between tourism and culture needs to be carefully managed in order to ensure long-term sustainability and cultural characterization, especially in local cultural festivals. In fact, "the development of an external orientation can threaten the relationship forged between local populations and their festivals" [17] (p. 299). By programming potentially overshadowing international acts, privileging visiting audiences and allowing the private sector to enter the ownership, festivals are likely to risk undermining this relationship. In this regard, our study supports the idea that cultural tourism itself can act as a barrier to commodification: It is likely to enable host communities to capitalize on tourists' desire for some form of "authentic" experience that will allow them to connect with the place and culture of their destination (for some recent reflections on authenticity, see [51,52]).

In terms of policy implications, our findings might prove to be useful in guiding decision makers into possible fundraising initiatives or, in general, in making decisions on future events' cultural and economic sustainability during their life cycle. The positive interaction between attendees' perception of a commodification risk and the mass gathering dimension implies that public institutions should implement privatization policies very carefully, especially when in the presence of huge tourist flows, where the event is likely to lose some of its traditional connotations.

Author Contributions: G.A. and G.U. conceived the original idea. Methodology: G.U. developed the theoretical framework and G.A. developed the theoretical formalism. G.A. and G.U. planned and carried out the survey, also providing financial resources. F.P. encouraged G.A. and G.U. to investigate some specific aspects which are key to this paper and contributed to the elaboration of some of the questionnaire items conceived by G.A. and G.U. Formal analysis: H.C. performed the data analysis under the supervision of G.A. and F.P. Writing: G.A. and G.U. prepared the original draft of the paper; F.P. reviewed and edited the draft. All authors discussed the results and contributed to the final manuscript.

Funding: This paper has been circulated previously under the title "Private Ownership of a Cultural Event: Do Attendees Perceive it as a Risky Lottery?". It obtained financial support by the project "Attractivité" and the project "Creative, Sustainable Economies and Societies" (CSES) coordinated by Robin Cowan, both funded through University of Strasbourg IDEX Unistra. G. Attanasi and G. Urso also acknowledge financial support by the French "Agence Nationale de la Recherche" (ANR), under grant ANR-18-CE26-0018-01 (project GRICRIS).

Acknowledgments: The authors would like to thank Sara Chironi, Giorgia De Giorgi and Duilio Riso for great support in the field interviews. We thank Michela Chessa, Nikolaos Georgantzís, Filippo Giordano, Andrea Guido, Penelope Hernandez, Sergio Torsello, and the seminar participants at the GIKA Conference 2014 in Valencia for useful discussions. This work was supported by the project "Attractivité" and the project "Creative, Sustainable Economies and Societies" (CSES) coordinated by Robin Cowan, both funded through University of Strasbourg IDEX Unistra. G. Attanasi and G. Urso also acknowledge financial support by the French "Agence Nationale de la Recherche" (ANR), under grant ANR-18-CE26-0018-01 (project GRICRIS). This research had not produced any financial benefit from its results.

Conflicts of Interest: The authors declare no conflict of interest. The funders had no role in the design of the study; in the collection, analyses, or interpretation of data; in the writing of the manuscript, or in the decision to publish the results.

\section{References}

1. Morrison, M.; Dowell, D.J. Sense of place and willingness to pay: Complementary concepts when evaluating contributions of cultural resources to regional communities. Reg. Stud. 2015, 49, 1374-1386. [CrossRef]

2. Cohen, E. Authenticity, equity and sustainability in tourism. J. Sustain. Tour. 2002, 10, 267-276. [CrossRef]

3. Coalter, F. Leisure studies, leisure policy and social citizenship: The failure of welfare or the limits of welfare? Leis. Stud. 1998, 17, 21-36. [CrossRef]

4. Andersson, T.D.; Getz, D. Tourism as a mixed industry: Differences between private, public and not-for-profit festivals. Tour. Manag. 2009, 30, 847-856. [CrossRef]

5. Xie, P.F.; Lane, B. A life cycle model for aboriginal arts performance in tourism: Perspectives on authenticity. J. Sustain. Tour. 2006, 14, 545-561.

6. Frost, W.; Laing, J. Avoiding burnout: The succession planning, governance and resourcing of rural tourism festivals. J. Sustain. Tour. 2015, 23, 1298-1317. [CrossRef] 
7. Eckel, C.C.; Grossman, P.J. Men, women and risk aversion: Experimental evidence. In Handbook of Experimental Economics Results; Plott, C., Smith, V., Eds.; Elsevier: New York, NY, USA, 2008; Volume 1, pp. 1061-1073.

8. Harrison, G.W.; Lau, M.I.; Rutström, E.E. Estimating risk attitudes in Denmark: A field experiment. Scand. J. Econ. 2007, 109, 341-368. [CrossRef]

9. Getz, D. The nature and scope of festival studies. Int. J. Event Manag. Res. 2010, 5, 1-47.

10. Silvers, J.; Bowdin, G.; O'Toole, W.; Nelson, K. Towards an international event management body of knowledge (EMBOK). Event Manag. 2006, 9, 185-198. [CrossRef]

11. Harris, R.; Jago, L.; Allen, J.; Huyskens, M. Towards an Australian event research agenda: First steps. Event Manag. 2000, 6, 213-221. [CrossRef]

12. Hede, A.; Jago, L.; Deery, M. An agenda for special event research: Lessons from the past and directions for the future. J. Hosp. Tour. Manag. 2003, 10, 1-14.

13. Getz, D. Event tourism: Definition, evolution, and research. Tour. Manag. 2008, 29, 403-428. [CrossRef]

14. Frey, B. The economics of music festivals. J. Cult. Econ. 1994, 18, 29-39. [CrossRef]

15. Acheson, K.; Maule, C.; Filleul, E. Cultural entrepreneurship and the Banff Television Festival. J. Cult. Econ. 1996, 20, 321-339. [CrossRef]

16. Garrod, B.; Fyall, A.; Leask, A. Scottish visitor attractions: Managing visitor impacts. Tour. Manag. 2002, 23, 265-279. [CrossRef]

17. Quinn, B. Problematising 'festival tourism': Arts festivals and sustainable development in Ireland. J. Sustain. Tour. 2006, 14, 288-306. [CrossRef]

18. McKercher, B.; Mei, W.S.; Tse, T.S. Are short duration cultural festivals tourist attractions? J. Sustain. Tour. 2006, 14, 55-66. [CrossRef]

19. Sims, R. Food, place and authenticity: Local food and the sustainable tourism experience. J. Sustain. Tour. 2009, 17, 321-336. [CrossRef]

20. Getz, D. Special events: Defining the product. Tour. Manag. 1989, 10, 125-137. [CrossRef]

21. Mckercher, B. Attitudes to a non-viable community-owned heritage tourist attraction. J. Sustain. Tour. 2001, 9, 29-43. [CrossRef]

22. Guiso, L.; Paiella, M. Risk aversion, wealth and background risk. J. Eur. Econ. Assoc 2008, 6, 1109-1150. [CrossRef]

23. Herrero, L.C.; Sanz, J.A.; Bedate, A.; Del Barrio, M.J. Who pays more for a cultural festival, tourists or locals? A certainty analysis of a contingent valuation application. Int. J. Tour. Res. 2011, 14, 495-512. [CrossRef]

24. Throsby, D. Economics and Culture; Cambridge University Press: Cambridge, UK, 2001.

25. Camacho-Cuena, E.; García-Gallego, A.; Georgantzís, N.; Sabater-Grande, G. An experimental test of response consistency in contingent valuation. Ecol. Econ. 2003, 47, 167-182. [CrossRef]

26. Camacho-Cuena, E.; García-Gallego, A.; Georgantzís, N.; Sabater-Grande, G. An experimental validation of hypothetical WTP for a recyclable product. Environ. Resour. Econ. 2004, 27, 313-335. [CrossRef]

27. Georgantzís, N.; Navarro-Martínez, D. Understanding the WTA-WTP gap: Attitudes, feelings, uncertainty and personality. J. Econ. Psychol. 2010, 31, 895-907. [CrossRef]

28. Richards, G. (Ed.) Cultural Tourism: Global and Local Perspectives; The Haworth Press, Inc.: New York, NY, USA, 2007.

29. Fairweather, J.R.; Swaffield, S.R. Visitors' and locals' experiences of Rotorua, New Zealand: An interpretative study using photographs of landscapes and Q method. Int. J. Tour. Res. 2002, 4, 283-297. [CrossRef]

30. Cohen, E. Authenticity and commodification in tourism. Ann. Tour. Res. 1988, 15, 371-386. [CrossRef]

31. Shepherd, R. Commodification, culture and tourism. Tour. Stud. 2002, 2, 183-201. [CrossRef]

32. Attanasi, G.; Casoria, F.; Centorrino, S.; Urso, G. Cultural tourism, local development and instantaneous social capital: A case study of a gathering festival in the South of Italy. J. Socio-Econ. 2013, 47, 228-247. [CrossRef]

33. Harrison, G.W.; Rutström, E.E. Risk aversion in the laboratory. In Research in Experimental Economics: Risk Aversion in Experiments; Harrison, G.W., Cox, J., Eds.; JAI Press: Bradford, UK, 2008; pp. 41-196.

34. Richards, G.; de Brito, M.; Wilks, L. (Eds.) Exploring the Social Impacts of Events; Routledge: London, UK, 2013.

35. Marbach, G. Le Ricerche di Mercato; Utet: Torino, Italia, 2000.

36. Polyzou, E.; Jones, N.; Evangelinos, K.I.; Halvadakis, C.P. Willingness to pay for drinking water quality improvement and the influence of social capital. J. Socio-Econ. 2011, 40, 74-80. [CrossRef] 
37. Dell'Olio, L.; Ibeas, A.; Cecín, P.; dell'Olio, F. Willingness to pay for improving service quality in a multimodal area. Transp. Res. Part C Emerg. Technol. 2011, 19, 1060-1070. [CrossRef]

38. Novello, S.; Fernandez, P.M. The influence of event authenticity and quality attributes on behavioral intentions. J. Hosp. Tour. Res. 2016, 40, 685-714. [CrossRef]

39. Silberberg, T. Cultural tourism and business opportunities for museums and heritage sites. Tour. Manag. 1995, 16, 361-365. [CrossRef]

40. Attanasi, G.; Bortolotti, S.; Cicognani, S.; Filippin, A. The Drunk Side of Trust: Social Capital Generation at Gathering Events; BETA WP 2017-21; University of Strasbourg: Strasbourg, France, 2017.

41. Attanasi, G.; Urso, G. L'impatto sociale del Festival ‘La Notte della Taranta' sulla comunità che lo ospita. Palaver 2015, 4, 179-222.

42. Sapienza, P.; Zingales, L.; Maestripieri, D. Gender differences in financial risk aversion and career choices are affected by testosterone. Proc. Natl. Acad. Sci. USA 2009, 106, 15268-15273. [CrossRef]

43. Riley, W.B.; Chow, K.V. Asset allocation and individual risk aversion. Financ. Anal. J. 1992, 48, 32-37. [CrossRef]

44. Hersch, J. Smoking, seat belts and other risky consumer decisions: Differences by gender and race. Manag. Decis. Econ. 1996, 17, 471-481.

45. Laing, J. Festival and event tourism research: Current and future perspectives. Tour. Manag. Perspect. 2018, 25, 165-168. [CrossRef]

46. EU Commission. Economic Crisis in Europe: Causes, Consequences and Responses. 2009. Available online: http://ec.europa.eu/economy_finance/publications/pages/publication15887_en.pdf (accesed on 19 February 2019).

47. OECD. The Economic Crisis and Recovery in OECD Regions and Cities. 2013. Available online: https://www.oecd.org/regional/ministerial/Monitoring-the-Crisis.pdf (accesed on 19 February 2019).

48. OECD. OECD Data. 2017. Available online: https://data.oecd.org/ (accesed on 19 February 2019).

49. ISTAT. General Government Net Borrowing and Debt in the EDP Notification According to Maastricht Treaty. 2010. Available online: https:/www.istat.it/en/files/2011/02/notifica_22_oct.pdf?title=Net+borrowing+and+ debt+in+the+EDP+Notification+-+22+Oct+2010+-+Full+text.pdf (accesed on 19 February 2019).

50. Patena, W.; Stawiarska, R. The public perception of privatization in Poland from 1991-2014. Finanse Rynki Finans. Ubezp. 2016, 1, 723-738. [CrossRef]

51. Girish, V.G.; Chen, C.-F. Authenticity, experience, and loyalty in the festival context: Evidence from the San Fermin festival, Spain. Curr. Issues Tour. 2017, 20, 1551-1556. [CrossRef]

52. Szmigin, I.; Bengry-Howell, A.; Morey, Y.; Griffin, C.; Riley, S. Socio-spatial authenticity at co-created music festivals. Ann. Tour. Res. 2017, 63,1-11. [CrossRef]

(C) 2019 by the authors. Licensee MDPI, Basel, Switzerland. This article is an open access article distributed under the terms and conditions of the Creative Commons Attribution (CC BY) license (http://creativecommons.org/licenses/by/4.0/). 